\title{
You Can Interact with Your TV and You May Like It an Investigation on Persuasive Aspects for an iDTV Application
}

\author{
Samuel B. Buchdid, Roberto Pereira, and M. Cecília C. Baranauskas \\ Institute of Computing, University of Campinas, \\ Av. Albert Einstein N1251, Campinas-SP, Brazil \\ \{buchdid, rpereira, cecilia\}@.ic.unicamp.br
}

\begin{abstract}
Interactive Digital TV (iDTV) is a technology that has many challenges that surround it and that may discourage the passive viewers to interact with TV. To face the challenging scenario of designing for iDTV, we draw on the Social Aware Computing (SAC) approach to design, looking at the problem and proposing solutions on various abstraction levels (informal, formal and technical) according to the viewpoint of different stakeholders, including prospective end users. This paper presents a motivational analysis conducted through Analytical and Empirical evaluations and Questionnaires, to understand whether and how an iDTV application designed through the SAC motivates users to interact with it. As results, our analysis pointed out application features that are likely to motivate users to interact, and features that emerged during the design process and were reflected on the application prototype. Moreover, we discuss whether and how the SAC design process may support iDTV applications that make sense to users and motivate them to interact.
\end{abstract}

Keywords: Interactive Digital TV, Persuasive Design, HCI, Socially Aware Computing, Organizational Semiotics, Participatory Design, Design Patterns.

\section{Introduction}

The Interactive Digital TV (iDTV) is an emerging technology considered a promising medium for the dissemination of information, potentially contributing to social and digital inclusion by reducing barriers to knowledge. However, iDTV presents some problems that impact directly on iDTV usage and may discourage the viewer to change his/her passive posture in front of the TV. Examples of problems include: i) those inherent to iDTV technology (e.g., the interaction limited by the remote control, the limited processing resources and memory, the low transmission speed); ii) those inherited from the culture of using the analogical TV (e.g., the lack of habit to interact with television content, the usual presence of other viewers in the same physical space); and iii) those associated with technological convergence where the TV is inserted (e.g., devices can either support the television usage or compete with it) $[5,10]$. Furthermore, every emergent technology suffers from a lack of references, processes and artifacts for supporting their application design [10]. 
To face these challenges, some authors point out the need for considering social, emotional and motivational issues in the design of iDTV applications, including the end user viewpoint and features of everyday life in order to promote the acceptance of this kind of application. Such elements include: i) design principles to support user interactivity during leisure pursuits in domestic settings [6]; ii) ethnographic studies in order to understand users' media behavior and expectations [2]; and iii) participatory design methodologies and interactive practices to propose design solutions [18]. We draw on Socially Aware Computing [1], grounded on Organizational Semiotics [11] and Participatory Design [14], to make a social responsible design of iDTV applications: a design that meets the needs of the different stakeholders involved and of the complex social context in which the application is/will be situated.

This paper presents and discusses results of an investigation on motivational aspects for promoting the use and adoption of iDTV applications. This investigation was grounded on the persuasive perspective proposed by Fogg [8], and considered three different kinds of evaluation: empirical evaluation, analytical evaluation, and questionnaires. As a result we have the intention to show motivational characteristics that emerged from iDTV application designed through the socially aware design.

The paper is organized as follows: Section 2 introduces the motivational theoretical and methodological background of our study; Section 3 shows the socially aware approach proposed to design an iDTV application in a TV Show's situated context; Section 4 describes the method for evaluating the prototype for an iDTV application; Section 5 presents and discusses the main findings from case study; and Section 6 presents our final considerations and directions for future research.

\section{Theoretical and Methodological Foundation}

By definition, motivation is "the act or process of giving someone a reason for doing something" [13]. Motivation emerges from internal needs (which are driven by an interest or enjoyment in the task) and external influences (which are influences of the environment to motivate the individual performing tasks to be rewarded or not to be punished) [17]. In this sense, there are several approaches investigating motivation from different theoretical viewpoints (e.g., biological, physiological, psychological, social) that complement or opposes each other. Some studies have proposed general theories to account for commonalities among all human motives, and others have studied specific motives such as hunger, sex, affiliation, and achievement [9].

According to Torning and Oinas-Kukkonen [21], there are at least four recognized key computer-based fields of research for persuasive systems and design: i) Humancomputer interaction: investigates ways of designing computer systems that are usable and understandable, including how information can be gathered for such designs. ii) Computer-mediated communication: investigates how technology affects modes of communication (synchronous and asynchronous) and impacts on them. iii) Information systems: approaches the software, databases and the content provided for the user in a systemic way, looking for designing a system that will bring benefits to both the organization and the end user (often working in their habitat). iv) Affective 
computing: investigating the creation of systems in order to recognize, interpret, and process human emotions.

Literature also presents models for providing a systematic way to think about the factors underlying behavior change in the process of designing and evaluating persuasive systems, even for those who do not have an understanding on human psychology. For instance, Persuasive Systems Design (PSD) model [15] provides an extensive conceptualization of technology-mediated persuasion. It can be used to prescribe persuasive designs and software requirements; it also supports evaluations by categorizing and mapping persuasive elements. Reeve [17] proposes a framework to understand motivation and emotion which has been used, for example, in the HCI field for the design of Residential Energy Feedback Systems [16]. Other example is the work of Scialdone and Zhang [19] that present a theoretic-motivational model that helps to identify elements (from primitive human needs to formation and attainment of a specific behavior and goal) that can to inform design decisions of Information and Communication Technologies.

The Conceptual Persuasive Model used in this study is named "Fogg Behavior Model" (FMB) [8]. The FMB aggregates important aspects of behavior change (e.g., ability) that can be handled directly by HCI concepts (e.g., usability). It is also used to identify problems in systems that fail to achieve the intended outcomes (e.g., iDTV). Thus, it seems to be a theoretical framework suitable for our study.

\subsection{Fogg Behavior Model}

The FBM considers three main factors (motivation, ability and triggers) that influence people's behavior change. The motivation factor is related to elements such as pleasure, pain, hope, fear, and social acceptance to perform the target behavior. The ability factor is related to simplicity in design, which makes the system easy for the user to perform the target behavior. Finally, a trigger is something that tells/incites people to perform the behavior right now (e.g., prompts, cues, and calls to action). In summary, the model assumes that to perform a target behavior the person must have sufficient motivation and ability, and must be driven by an effective trigger. Moreover, all the three factors must be simultaneously present for the behavior to occur.

In this sense, in a design process of persuasive technology, the FBM may help the designer to direct his/her efforts more efficiently. For example, if the motivation factor is low, the designer can focus on this aspect during the design process. The same may happen to the ability and trigger factors. For clarifying the motivation, ability and trigger factors, Fogg [8] associated key elements to them - see Table 1.

People have different profiles: they can be more easily or hardly motivated, or have more or less abilities, or may be more or less stimulated by a same trigger. These factors vary according to the individual, but they also vary according to the context. Thus, designers should identify the audience and the context (e.g., media type, use time and location) because the more diverse they are, more complex is to design a motivational intervention [8]. 
Table 1. All three FMB's factors and their elements

\begin{tabular}{|c|c|c|}
\hline $\begin{array}{l}\text { Fac- } \\
\text { tors }\end{array}$ & Elements & Description \\
\hline \multirow{3}{*}{ 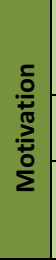 } & $\begin{array}{l}\text { Pleasure / } \\
\text { Pain }\end{array}$ & $\begin{array}{l}\text { They are (almost) an immediate motivator; It works as a primitive response and it is } \\
\text { similar to activities related to self-preservation and propagation of our genes (e.g., } \\
\text { hunger and sex). }\end{array}$ \\
\hline & Hope / Fear & $\begin{array}{l}\text { They are characterized by anticipation of an outcome (e.g., hope and fear are the expec- } \\
\text { tation of something good or bad to happen, respectively). }\end{array}$ \\
\hline & $\begin{array}{l}\text { Social Ac- } \\
\text { ceptance / } \\
\text { Rejection }\end{array}$ & $\begin{array}{l}\text { They control our social behavior, from the clothes we wear to the language we use. In } \\
\text { practice, people are motivated to maintain social accepted behaviors and avoid situations } \\
\text { they are socially rejected. }\end{array}$ \\
\hline \multirow{6}{*}{ 高 } & Time & $\begin{array}{l}\text { It refers to demand of time for a target behavior to occur; if we don't have available time, } \\
\text { then, the behavior is not simple (e.g.; form that has } 100 \text { fields). }\end{array}$ \\
\hline & Money & $\begin{array}{l}\text { It is associated with financial resources; if a target behavior costs money and we don't } \\
\text { have money, then the behavior is not simple. }\end{array}$ \\
\hline & $\begin{array}{c}\text { Physical } \\
\text { Effort }\end{array}$ & $\begin{array}{l}\text { It refers to physical effort to reach the target behavior, which may not be simple (e.g., } \\
\text { travel long distances without transportation). }\end{array}$ \\
\hline & Brain Cycles & $\begin{array}{l}\text { It refers to mental ability to reach the target behavior; If performing a target behavior } \\
\text { causes us to think hard, that might not be simple (e.g., a hard math puzzle) }\end{array}$ \\
\hline & $\begin{array}{l}\text { Social Devi- } \\
\text { ance }\end{array}$ & $\begin{array}{l}\text { It refers to the difficulty of getting a behavior that breaks society's rules (e.g., wearing } \\
\text { pajamas to a city council meeting). }\end{array}$ \\
\hline & Non-Routine & $\begin{array}{l}\text { Refers to the fact that a behavior becomes simpler if it is part of the people's daily } \\
\text { routine (e.g., buying gas at the same station) }\end{array}$ \\
\hline \multirow{3}{*}{ 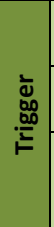 } & Spark & $\begin{array}{l}\text { It should be used when a person lacks motivation to perform a target behavior. It should } \\
\text { be used in tandem with a motivational element (e.g., videos that inspire hope). }\end{array}$ \\
\hline & Facilitator & $\begin{array}{l}\text { It is proper for users that have high motivation but lack ability. The goal is to trigger the } \\
\text { behavior while making the behavior easier to occur (e.g. one click can get the job done). }\end{array}$ \\
\hline & Signal & $\begin{array}{l}\text { It works best when people have both the ability and the motivation to perform the target } \\
\text { behavior. The signal doesn't seek to motivate people or simplify the task, but to serve as a } \\
\text { reminder (e.g., traffic light that turns red or green). }\end{array}$ \\
\hline
\end{tabular}

\section{Situated Design}

The Socially Aware Computing (SAC) [1] is an approach to make a socially responsible, participatory and universal design as a process and a product. The SAC draws on Organizational Semiotics (SO) [11] to understand the context in which the technical system is/will be inserted and the main forces that direct or indirectly act on it; and Participatory Design (PD) [14] to understand the situated context. Workshops involving heterogeneous groups of people who may influence and/or may be influenced by the problem being discussed and/or the solution to be designed are proposed within SAC.

SAC understands design as a wave that starts in the society and progresses through the informal and formal layers in order to build the technical system - see "SAC's instance" layers in Fig. 1. The informal level refers to social norms that regulate behavior, beliefs, values, habits, culture, etc., that drive people's behavior. The formal level involves rules and procedures created to explain mechanistic and repetitive tasks. The technical system is only part of the formal level of an organization, which can be automated. Once the technical system is projected, the wave returns impacting on the informal and formal layers, on society. 
The study scenario was the "Terra da Gente" (TdG) program ("Our Land" in English), one of the several TV shows produced by EPTV: a Brazilian broadcasting company whose program reaches a region in Brazil that includes 300 cities and more than 10 million citizens [7]. The TdG program explores local fauna and flora, fishing and regional cuisine, and reaches people from all ages, mainly adults and elderly people [20]. The object of study is the design of an iDTV application for TdG, named iTG, which should reach the TV show's audience. For designing the iTG, we conducted different activities during four participatory workshops in the situated context of EPTV. Ten participants involved directly and indirectly in the problem domain, with different profiles (e.g., designer, engineers, researchers, TV program director and interns), participated in these workshops.

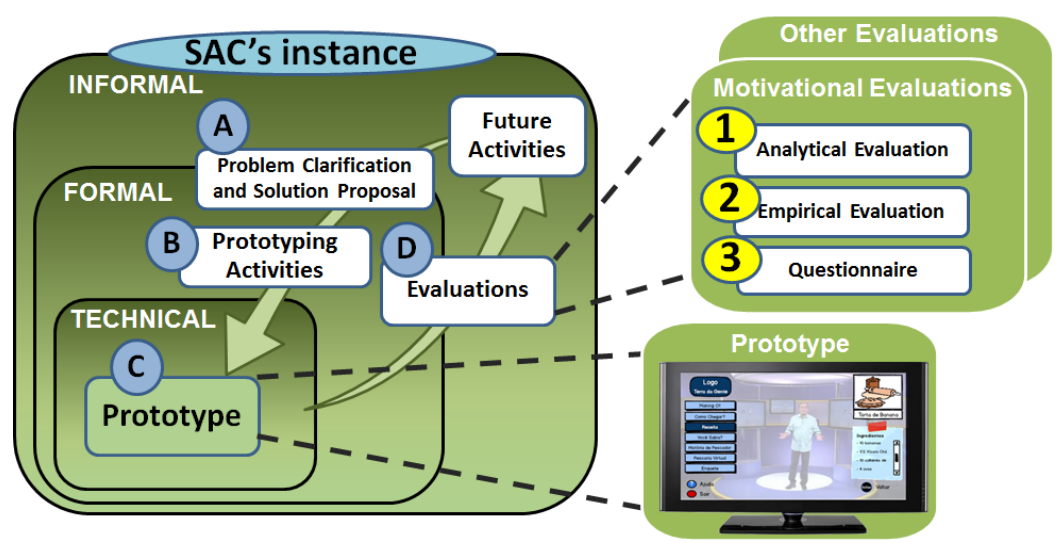

Fig. 1. Situated instance of SAC's meta-model for design

Fig. 1 presents Baranauskas' SAC approach to design [1] instantiated for the situated context of EPTV. In this context, we used artifacts from OS and created new practices for supporting participatory and situated design activities. For instance, activities encompassed the problem understanding and clarification, the analysis and organization of requirements for the application to be designed, and the generation of design ideas for the first prototype of the iTG (see "A" detail in Fig. 1). The produced ideas were materialized in prototyping activities through an adapted version of the Brain Draw participatory technique [3] ("B" detail) that made use of design patterns for iDTV [10]. Both Balsamiq ${ }^{\circledR}$ and CogTool $^{\circledR}$ tools were used to create the interactive prototype ("C" detail). The final prototype (Fig. 2) was evaluated interactively by representatives from the target audience, by specialists in HCI, and also in a participatory practice with the workshops participants. These evaluation practices ("D" detail in Fig. 1) were important to identify problems and propose solutions before producing and broadcasting the first version of iTG application. The materials produced in these activities were reported in [3] and [4].

Fig. 2 highlights points that were reflected in the final prototype (from " $A$ " to " $F$ " details) and that emerged from different stages of the design process. For instance, " $\mathrm{A}$ " detail draws attention to a simple layout, which was suggested in problem clarification 
and solutions proposal stage, to prevent deviation of the television content and to complement it. The choice of remote control as the main interaction device, due to costs to viewers, also happened in the initial stage. The definitions of interface elements disposal and menu options emerged during the stage of drawing up ideas and prototyping ("B" detail). In this same stage, suggestions for the sub-page layouts ("D" and "E" details), and initial icon (see "F" detail) were made. The navigation project, which includes the remote control keys (see "C" detail), was defined in a design activity with Patterns and was refined during the construction of the final prototype.

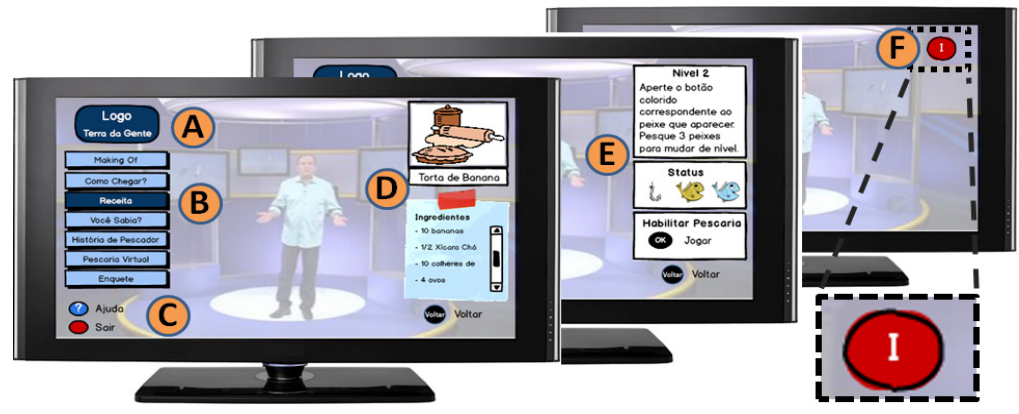

Fig. 2. Application's screenshots

In addition to the situated and participatory activities, we applied questionnaires in each workshop. In the first we created a graph based on the FBM model, and asked the participants to represent the TdG viewer's behavior regarding the insertion/use of an iDTV application. Participants should mark an " $X$ " to indicate where they think the behavior actually is, and a "Y" where they think the behavior should be (the desirable situation) (see Fig. 3).

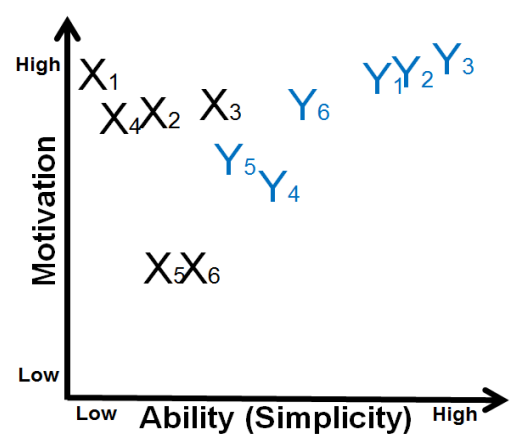

Fig. 3. Answers from the participants prospecting viewers behavior

Fig. 3 shows the answers of six participants: on the one hand, the " $\mathrm{X}$ " marks show that the participants believe the viewers to have high motivation to interact with an iDTV application because the audience's profile is exploratory and adventurous. However, the inexperience with iDTV applications indicates that viewers still have low skill. On the other hand, the "Y" marks indicate that participants believe the 
viewers will be motivated with the new technology and will acquire the necessary skill as soon as the application is available, achieving the activation line to promote the behavior change.

\section{Motivational Evaluations}

In this paper, we focus on the motivational evaluation of the interactive prototype from three different perspectives ("1", "2" and "3" details in Fig. 1) that were conducted to: Goal 1: indicate possible problems of interaction from motivational analysis. Goal 2: identify whether the prototyped application was able to motivate users to interact with it and watch the television program. Goal 3: prospect whether and how the socially aware design process is able to deal with persuasive issues that appeal the user. Goal 4: identify the motivational elements that appeared on the application, showing which of these elements appeared during the design process being reflected in the final prototype; and, Goal 5: raise useful ideas to promote the behavioral change on users of iDTV applications.

Analytical evaluation (" 1 " detail in Fig. 1): the prototype was analyzed according to 3 factors (motivation, ability and trigger) and theirs subfields (e.g., pleasure vs. pain, hope vs. fear, social acceptance vs. rejection) proposed in Fogg's model [8]. For this, HCI specialists explored all prototype screens and the possible interactions on them, mapping motivational features found in the prototype according to FBM.

Empirical evaluation ("2" detail in Fig. 1): an evaluation with prospective end users interacting with the prototype was conducted for understanding the aspects that motivated, motivate, and supposedly will continue motivating them. The ease of use and triggers were also observed during the evaluation activity through the "Thinking Aloud" technique [12]. Participants' interaction and facial expressions were recorded under their informed consent. Here, users were invited to freely navigate through the prototype, and they were asked to say whatever they were looking at, thinking, doing, and feeling as they went about their task. After the activity, HCI experts analyzed the recordings and mapped motivational aspects according to FMB's factors and elements.

Questionnaires ("3" detail in Fig. 1): after the empirical evaluation, the prospective end users were asked to answer a questionnaire. The questionnaire aimed at identifying their general impressions about the application (subjective satisfaction), whether it discouraged or motivated them, and aspects of its usability. Questions were related to the user profile (e.g., age, formal education, previous experience using iDTV applications and mobiles, frequency that s/he watched the TdG program, etc.) and other general impressions (e.g.; whether the participants really enjoyed, liked moderately, were indifferent, didn't like so much or disliked the application; whether they had any suggestions for the application). The questionnaire also presented questions related to motivational issues, such as: 
- Motivational Axis: What would be your main motivation to access the iTG application? And to continue accessing it? Do you consider that the iTG application will: i) motivate viewers to watch the TV Show, ii) indifferent (neither disturb nor motivate), or iii) disturb viewers when watching the TV Show. In what way?

- Ability (simplicity) Axis: Did you have any problem to interact with the iTG? Was (or was not) easy to interact with it? How? Why?

\section{$5 \quad$ Results and Discussion}

10 participants explored the prototype: 3 participants are 21-30 years old, 5 are 31-40 years old, 1 is 41-50 years old, and 1 participant is over 60 years old. Regarding their formal education: 1 has high school, 3 have bachelor's degree, 1 has specialization course, 3 have master's degree and 1 participant has a doctor's degree. None participant had previous experience using iDTV applications; 8 participants were aware of them, but had never seen any application; and 2 participants had seen them before. Furthermore, 6 have been watching the TdG program, although not often; 3 participants watch once a month; and 1 participant do not watch TdG.

The Analytical and Empirical Evaluations show that there are several pros and cons related to the motivational issues in the iTG context. Tables 2 and 3 present a summary of the results.

Table 2. Analytical and Empirical Evaluation - Motivational axis

\begin{tabular}{|c|c|c|c|c|}
\hline \multirow{2}{*}{ 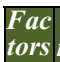 } & \multirow{2}{*}{$\begin{array}{l}\text { Ele- } \\
\text { ments }\end{array}$} & & \multicolumn{2}{|r|}{ Description } \\
\hline & & & Analytical & Empirical \\
\hline \multirow{6}{*}{ : } & \multirow{2}{*}{ 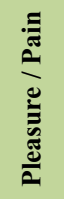 } & ㄴ. & $\begin{array}{l}\text { - Application content that comple- } \\
\text { ments the TV Shows } \\
\text { - Entertainment features (e.g., Games } \\
\text { and Pool) } \\
\text { - iDTV application is an innovation }\end{array}$ & $\begin{array}{l}\text { - Direct interaction with TV Show (e.g., Pools, } \\
\text { Quiz, Fisherman Story) } \\
\text { • Users feel motivated (happy) with formal (e.g., } \\
\text { Localization/Mapp and Information/Curiosity) or } \\
\text { informal (e.g., Fishing Game) content }\end{array}$ \\
\hline & & $\overline{8}$ & & $\begin{array}{l}\text { When users want to use the application features, } \\
\text { but they don't have the ability for it; }\end{array}$ \\
\hline & \multirow{2}{*}{ 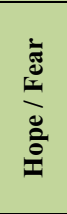 } & $\stackrel{0}{2}$ & $\begin{array}{l}\text { "Help" and tips can minimize the } \\
\text { fear of non-expert users to interact } \\
\text { with a unknown technology }\end{array}$ & $\begin{array}{l}\text { - Users hope that application content is related (or } \\
\text { complement) the current TV Show. If necessary } \\
\text { with next and previous TV Shows } \\
\text { - The users feel motivated when they receive } \\
\text { constant feedback from the application }\end{array}$ \\
\hline & & $\overline{8}$ & $\begin{array}{l}\text { Fear of iDTV application competes } \\
\text { and distracts viewers from TV } \\
\text { Show }\end{array}$ & $\begin{array}{l}\text { - Non-technological users can be afraid to interact } \\
\text { with new devices (cultural issues) }\end{array}$ \\
\hline & \multirow{2}{*}{ 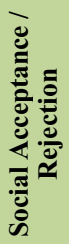 } & $\stackrel{2}{2}$ & $\begin{array}{l}\text { - Simple application (allowing digital } \\
\text { and social inclusion). } \\
\text { - Content and language was designed } \\
\text { to be familiar to TdG viewers }\end{array}$ & $\begin{array}{l}\text { Users are happy when they easily reach their goals } \\
\text { (socially judged). }\end{array}$ \\
\hline & & อี & $\begin{array}{l}\text { New technologies may be rejected } \\
\text { by users }\end{array}$ & $\begin{array}{l}\text { - Non-experts users are afraid of making mistakes } \\
\text { (socially judged); they try to reach the goal by } \\
\text { using trial and error approach. } \\
\text { - Labels should be appropriate to target audience }\end{array}$ \\
\hline
\end{tabular}


In addition, the specialists understood that there are only 3 triggers in the application: i) initial icon: to call viewers to interact; ii) loading the application: to show that the application is starting; and iii) fishes appearing on the screen (in fishing game): to motivate viewers to continue watching the TV Show. All of them are trigger signals. The analysis of the prospective users interacting with the application indicated that the element designed to be the initial icon (see "F" detail in Fig. 1) would be sufficient for expert users, but not for the non-expert ones. Sparks and Facilitator triggers were not designed in the application because they are expected to come from the TdG magazine and the web portal.

Table 3. Analytical and Empirical Evaluation - Ability axis

\begin{tabular}{|c|c|c|c|c|}
\hline \multirow{2}{*}{\multicolumn{2}{|c|}{\begin{tabular}{|l|l|} 
Fac & Ele- \\
tors & ments \\
\end{tabular}}} & & \multicolumn{2}{|r|}{ Description } \\
\hline & & & Analytical & Empirical \\
\hline \multirow{11}{*}{$\frac{3}{2}$} & \multirow[t]{2}{*}{$\stackrel{\mathscr{\Xi}}{\Xi}$} & & $\begin{array}{l}\text { - Simple application takes } \\
\text { less time for interaction. } \\
\text { - Structured and synthetic } \\
\text { informations dispend less } \\
\text { time from users. }\end{array}$ & $\begin{array}{l}\text { - Having few information and requiring few interaction steps } \\
\text { make it simple the use } \\
\text { - Application allows taking notes (e.g., Localization/Maps and } \\
\text { Receipt) without access to the internet. } \\
\text { - User can open the applications only when and if they want. } \\
\text { - Immediacy on TV of some features are important to appli- } \\
\text { cation (e.g., Pool, Quiz, Informations) }\end{array}$ \\
\hline & & $\tilde{8}$ & $\begin{array}{l}\text { - Application will run just } \\
\text { when TV show is running. }\end{array}$ & $\begin{array}{l}\text { - Application is available only when the TV show is running } \\
\text { - Non-expert users dispend time trying randomly options. }\end{array}$ \\
\hline & 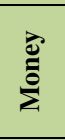 & & $\begin{array}{l}\text { - No money is necessary to } \\
\text { access the application } \\
\text { - Gifts can stimulate the } \\
\text { users to interact }\end{array}$ & $\begin{array}{l}\text { - Some users like when they earn gifts or money (e.g., a gift in } \\
\text { the fishing game designed for the application) }\end{array}$ \\
\hline & \multirow{2}{*}{ 氡 } & : & $\begin{array}{l}\text { - Application has low } \\
\text { hierarchical levels } \\
\text { - Layout chosen to not } \\
\text { disturb the TV content } \\
\end{array}$ & $\begin{array}{l}\text { - The application has few interaction levels: several interac- } \\
\text { tion steps can disturb users from TV Show content. }\end{array}$ \\
\hline & & $\tilde{8}$ & $\begin{array}{l}\text { - Blind and handicapped } \\
\text { users will have difficulties } \\
\text { to interact }\end{array}$ & $\begin{array}{l}\text { Non-expert users will have difficulties to find uncommon } \\
\text { remote control keys (e.g., the color keys). }\end{array}$ \\
\hline & \multirow{2}{*}{ 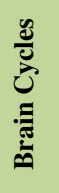 } & 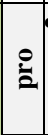 & $\begin{array}{l}\text { The application was } \\
\text { designed to be simple } \\
\text { (e.g., use of Arrows and } \\
\text { OK keys) }\end{array}$ & - Intuitive layout favours the interaction \\
\hline & & $\tilde{8}$ & $\begin{array}{l}\text { - Remote control requires } \\
\text { high cognitive abilities }\end{array}$ & $\begin{array}{l}\text { - In the beginning non-experts feel lost interacting with the } \\
\text { new technology }\end{array}$ \\
\hline & \multirow{2}{*}{ 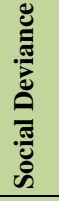 } & 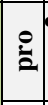 & $\begin{array}{l}\text { - Remote control is the } \\
\text { device more closer to } \\
\text { viewers }\end{array}$ & \\
\hline & & $\tilde{\Xi}$ & $\begin{array}{l}\text { - Interacting with TV is not } \\
\text { in the culture of classic } \\
\text { viewers (analogical TV) }\end{array}$ & $\begin{array}{l}\text { - Elderly users suffer more influences from analogical TV } \\
\text { habits (e.g., passivity) }\end{array}$ \\
\hline & \multirow{2}{*}{ 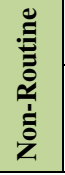 } & $\stackrel{0}{2}$ & & $\begin{array}{l}\text { - Interacting with iDTV from second time makes the activity } \\
\text { easier }\end{array}$ \\
\hline & & $\tilde{\Xi}$ & $\begin{array}{l}\text { - Interact with iDTV applica- } \\
\text { tions is not part of the } \\
\text { people's routine yet. }\end{array}$ & $\begin{array}{l}\text { The use of uncommon remote control keys (e.g., colour } \\
\text { keys) may confuse non-expert users }\end{array}$ \\
\hline
\end{tabular}


The Questionnaire answered by the representatives from the target audience reinforced a favorable opinion about the interactive prototype. The 10 prospective users were able to understand and explore the prototype, indicating points related to both motivation and simplicity. From their responses to the Motivational axis on the evaluation questionnaire, $7(70 \%)$ answered they consider that the iTG application would motivate viewers to watch the TV Show, and 3 (30\%) answered it would be indifferent (neither disturb nor motivate). Participants suggested that their main motivation to access the iTG application would be: i) to access relevant content (curiosities, recipes, game fishing and exclusive content); ii) to view part of the content they missed in the TV Show; iii) to take note of information that is difficult to annotate during the TV show (e.g., recipe and directions); iv) to learn more about a new subject; v) to view the information quickly without watching the entire TV program. The last one conflicts with the TV Show interests. To continue accessing the iTG, users answered that the application should be updated for each new program with extra curiosities, new information, new games, and different recipes. From their responses related to the Ability axis, $8(80 \%)$ answered they consider the iTG easy to interact, and 2 (20\%) answered they had a few problems to interact with it. Problems were usually related to starting the application and choosing options referred by uncommon remote control keys (e.g., color and special keys).

\subsection{Discussion}

The evaluations presented in this paper were an important stage in the design process because they supported the understanding of motivational issues that were present or missing in the designed prototype. The three evaluations complemented each other, addressing specific points, from different perspectives, indicating possible problems of interaction (achieving our "Goal 1") and contributing to improve both the final application and the design process. For example, the evaluation conducted by HCI experts indicated possible problems of interaction and attention for the users (e.g., "The remote control requires high cognitive abilities"). These problems were reinforced in the evaluation with the prospective end users (e.g., "Non-expert users will have difficulties to find uncommon remote control keys, e.g., the color keys"), and other new issues emerged, such as "Labels should be appropriated to target audience".

The evaluation with prospective end users provided us information for achieving the "Goal 2" and showed a correct expectation from the professionals before design process - high motivation and a low ability (see Fig. 3). Although users found the application intuitive and easy to use, they had initial difficulties to interact with the prototype, in parts because of their lack of experience with iDTV applications. On the one hand, after a few interactions, users got more comfortable with the application and started to explore it, visiting its different features; this was reinforced by their answers to the questionnaire that stated the application is easy to interact and would motivate viewers to watch the TV Show. On the other hand, when some users feel lost, they try change the channel, turn off the TV device, try many remote key options or visit parts of application randomly. In general terms, this evaluation indicated that the prototype was able to motivate novice users to interact with it and watch to the television program. 
As the answer to out "Goal 3", the practices conducted according to the SAC perspective, favored the design of a prototype that is aware of the several iDTV challenges, including the technological ones and the diversity of the audience. The SAC holistic view, from the problem clarification to the prototype evaluation, allowed to deal with television problems (from technical to formal) and to propose an application that complies with technical questions and takes into account its target audience. The participatory activities, considering different stakeholders (e.g., designer, engineers, researches, and other stakeholders) encouraged the interaction among the participants and favored the existence of different views for the problem, where new solutions and ideas were contrasted and negotiated throughout the design process. For instance, the Fishing Game and the Pool were features that emerged from the design process ("Goal 4") and generated controversy among workshop participants; nevertheless, they attracted attention from the users and pleased them. Because of its participatory and situated nature, the instance of SAC favored the design of features suitable to the TV Show (e.g., content and layout), and that motivated users during tests ("Goal 5"). This result suggests that the situated context favors the understanding of important aspects related to the values, habits, culture, needs, expectations, etc., from different stakeholders in the organization. These aspects would hardly be identified in a conventional design process detached from the organizational context.

During the design workshops, a resistance from participants to add motivational issues in the iTG application was identified. There are high investments from the company for producing and engineering content in order to please the audience, but as the iDTV application is still an evolving technology, the company believes it requires caution when investing.

\section{Conclusion}

While the iDTV comes as a promise to face social barriers to access the participatory and universal access to knowledge, it also suffers from problems that are inherent and that discourages user to interact with television applications. In this scenario, applications that promote behavior change and motivate viewers to interact are welcome. Design initiatives that understand the context in which the problem is inserted, the interests of key stakeholders and diversified audiences can be a differential to motivate viewers to interact effectively with the TV. In this paper, we explored the Fogg's persuasive approach on an iDTV application designed from a SAC [1] perspective.

The SAC approach generated an application with features in all motivational axes (motivation, ability and triggers), even without explicitly using any motivational artifact during the design process. In fact, most users responded positively to the questionnaire regarding their experience with the prototype. User also pointed out benefits in having an application that complements the television content. The analysis according to the FBM met the expectations for mapping motivational issues raised by the different evaluations and produced useful information for further design cycles. In future studies we intend to identify and adapt other persuasive techniques that can contribute along the SAC design process.

Acknowledgment. This research is partially funded by CNPq (\#165430/2013-3) and FAPESP (\#2013/02821-1). The authors specially thank the EPTV team, and the all participants who collaborated and authorized the use of their data in this paper. 


\section{References}

1. Baranauskas, M.C.C.: Socially Aware Computing. In: VI International Conference on Engineering and Computer Education (ICECE 2009), pp. 1-5 (2009)

2. Bernhaupt, R., Weiss, A., Pirker, M., Wilfinger, D., Tscheligi, T.: Ethnographic Insights on Security, Privacy, and Personalization Aspects of User Interaction in Interactive TV. In: 8th International Interactive Conference on Interactive TV and Vide0 (EuroiTV 2010), pp. 187-196. ACM Press, New York (2010)

3. Buchdid, S.B., Pereira, R., Baranauskas, M.C.C.: Playing Cards and Drawing with Patterns: Situated and Participatory Practices for Designing iDTV Applications. In: 16th International Conference on Enterprise Information Systems (ICEIS 2014) (in press, 2014)

4. Buchdid, S.B., Pereira, R., Baranauskas, M.C.C.: Creating an iDTV Application from Inside a TV Company: A Situated and Participatory Approach. In: 15th International Conference on Informatics and Semiotics in Organisations (ICISO 2014) (in press, 2014)

5. Cesar, P., Chorianopoulos, K., Jensen, J.F.: Social Television and User Interaction. Computers in Entertainment-Social Television and User Interaction 6(1), 1-10 (2008)

6. Chorianopoulos, K.: Interactive TV Design That Blends Seamlessly with Everyday Life. In: Stephanidis, C., Pieper, M. (eds.) ERCIM Ws UI4ALL 2006. LNCS, vol. 4397, pp. 43-57. Springer, Heidelberg (2007)

7. EPTV Portal, http://www. viaeptv.com

8. Fogg, B.J.: A behavior model for persuasive design. In: 4th International Conference on Persuasive Technology (Persuasive 2009), Article No. 40, pp. 1-7. ACM Press (2009)

9. Kassin, S.: Essentials of Psychology. Prentice Hall, Upper Saddle River (2004)

10. Kunert, T.: User-Centered Interaction Design Patterns for Interactive Digital Television Applications. Springer, Berlin (2009)

11. Liu, K.: Semiotics in Information Systems Engineering. Cambridge University Press, Cambridge (2000)

12. Lewis, C.H.: Using the "Thinking Aloud" Method in Cognitive Interface Design. IBM Research Report RC-9265, Yorktown Heights, NY (1982)

13. Merriam-WebsterDictionary, http://www. merriam-webster.com

14. Muller, M.J., Haslwanter, J.H., Dayton, T.: Participatory Practices in the Software Lifecycle. In: Helander, M.G., Landauer, T.K., Prabhu, P.V. (eds.) Handbook of HumanComputer Interaction, 2nd edn., pp. 255-297. Elsevier, Amsterdam (1997)

15. Oinas-kukkonen, H., Harjumaa, M.: Persuasive Systems Design: Key Issues, Process Model, and System Features. Communications of the Association for Information Systems 24, article 28 (2009)

16. Piccolo, L.S.G., Baranauskas, M.C.C.: Basis and Prospects of Motivation Informing Design: Requirements for Situated Eco-feedback Technology. In: 11th Brazilian Symposium on Human Factors in Computer Systems (IHC 2012), pp. 137-146. ACM Press, New York (2012)

17. Reeve, J.: Understanding Motivation and Emotion, 5th edn. Wiley, Hoboken (2009)

18. Rice, M., Alm, N.: Designing new interfaces for digital interactive television usable by older adults. Computers in Entertainment-Social Television and User Interaction 6(1), article 6, 1-20 (2008)

19. Scialdone, M., Zhang, P.: Deconstructing Motivations of ICT Adoption and Use: A Theoretical Model and its Applications to Social ICT. In: iConference, University of Illinois (2010)

20. Terra da Gente Portal, http: / / www . terradagente.com.br

21. Torning, K., Oinas-Kukkonen, H.: Persuasive system design: state of the art and future directions. In: 4th International Conference on Persuasive (Persuasive 2009), article 30. ACM Press, New York (2009) 